\title{
ACACIA SENEGAL BARK EXTRACT IN REGULATION OF HYPOTHYROIDISM: AN EXPERIMENTAL APPROACH
}

\section{DHEERAJ JANGID*, ASHOK PUROHIT}

Department of Zoology, Jai Narain Vyas University, Jodhpur, Rajasthan, India. Email: dheerajnjangid@gmail.com

Received: 24 July 2018, Revised and Accepted: 04 September 2018

\begin{abstract}
Objective: The objective of the present study was to evaluate the thyroid hormone stimulating efficacy of Acacia senegal (Gum Arabic) bark extract in 6-n-propyl-2-thiouracil (PTU)-induced hypothyroid albino rats.

Methods: Ethanolic extract of $A$. senegal bark was given to PTU-induced hypothyroid albino rats at the dose of 500 mg/kg body weight. The animals were divided into control, PTU, and A. senegal bark extract treated and standard drug Eltroxin-treated groups for 60-day experimentation. The serum
\end{abstract} thyroxin levels, organ's weight, and serum biochemistry were carried out.

Results: Oral administration of $A$. senegal bark extract caused a highly significant increase $(\mathrm{p} \leq 0.001)$ in serum triiodothyronine $\left(\mathrm{T}_{3}\right)$ and tetraiodothyronine $\left(\mathrm{T}_{4}\right)$, and significant changes were also observed in organ's weight with biochemical parameters as compared to hypothyroid albino rats and results were approximate to the standard drug Eltroxin.

Conclusion: These results evaluate that ethanolic extract of $A$. senegal bark helps to compensate or increases the serum thyroxin level in management of hypothyroidism.

Keywords: Acacia senegal bark, Hypothyroid, 6-N-propyl-2-thiouracil, Eltroxin.

(C) 2019 The Authors. Published by Innovare Academic Sciences Pvt Ltd. This is an open access article under the CC BY license (http://creativecommons. org/licenses/by/4. 0/) DOI: http://dx.doi.org/10.22159/ajpcr.2019.v12i1.28709

\section{INTRODUCTION}

Hypothyroidism is a worldwide issue which affects more women than men. It is not only caused by cluster of iodine deficiencies but also due to the insufficient level of thyroid-stimulating hormone (TSH) which yield low triiodothyronine $\left(\mathrm{T}_{3}\right)$ and tetraiodothyronine $\left(\mathrm{T}_{4}\right)$ hormone production resulting in mental and physical growth retardation [1]. In India, approximately 42 million people suffer from thyroid disease. Hypothyroidism is clear state of myxedema which may lead to multisystem failure or subclinical condition [2]. Hypothyroidism is identified by evaluating the thyroid hormone level in the blood and treated by a synthetic thyroid hormone. The Third National Health and Nutrition Examination Survey III stated that there is about $4.6 \%$ prevalence of hypothyroidism. It may extend from mild or subclinical to overt hypothyroidism. Hypothyroidism is categorized on the basis of occurrence with time as congenital or acquired, and according to the level of endocrine dysfunction as primary or central hypothyroidism. When the thyroid gland does not function properly, the level of serum TSH starts to elevate and this elevation is indicative of hypothyroidism. Mild thyroid failure or subclinical hypothyroidism is recognized with increased level of serum TSH in the blood, but the level of serum tetraiodothyronine $\left(\mathrm{T}_{4}\right)$ and triiodothyronine $\left(\mathrm{T}_{3}\right)$ remains normal or decreased [3]. Hypothyroidism has a number of signs and symptoms such as depression, anxious mood, weight gain, and poor ability to concentrate [4]. It is also the most common thyroid hormone metabolic disorder which occurs during pregnancy and causes congenital hypothyroidism that affects the growth of children [5].

At present, the necessity of plants in the remedy of diseases is rising like "back to nature" as a substitute for synthetic drugs which may be detrimental than the disease itself [6] as well as the longterm use of synthetic drugs may cause many other side effects. On the other hand, there are many plant products suggested by Ayurveda to cure diseases without any side effects. Thus, there is a need to develop a new plant drug with less or no side effects and approachable for patients which can helps to cure hypothyroidism. Acacia senegal L. (Fabaceae) tree, commonly known as Gum Arabic, Kumath, and Rfaudraksha, is found in drought or arid regions of the Thar Desert. Its bark, seed, leaves, fruit, and gum contain polyphenols, flavonoids, tannins, saponins, and alkaloids [7]. It was also reported that $A$. senegal bark contains antioxidants and used to treat bedsores and wounds [8], antimicrobial, anti-Fasciola activity [9], and also antidiabetic property [10], but its effect on thyroid hormone is still not known properly. Keeping these things in context, the present analysis copes with the impact of $A$. senegal bark extract on 6-n-propyl-2-thiouracil (PTU)-induced hypothyroidism in albino rats as a working model, if any. Serum $\mathrm{T}_{3}$ and $\mathrm{T}_{4}$ levels were analyzed with serum biochemistry.

\section{METHODS}

\section{Extraction of plant material}

A. senegal bark was taken from the area of Jai Narain Vyas University, Jodhpur, Rajasthan State, India, and authenticated by the Department of Botany, JNVU, Jodhpur. The bark was ground to powder and extracted in $70 \%$ ethanol for $24-36 \mathrm{~h}$ by Soxhlet extraction method. Then, ethanol was separated under reduced pressure to obtain a brownish crude residue which was dissolved in distilled water and orally administered to the animals.

\section{Model animals}

Healthy adult albino rats, Rattus norvegicus of Sprague Dawley strain, weighing about 150-250 g were used as working model. Animals were kept in polypropylene cages measuring 12 " $\times 10^{\prime \prime} \times 8$ " under controlled temperature $\left(24 \pm 1^{\circ} \mathrm{C}\right)$, humidity at $40-60 \%$ with $12: 12 \mathrm{~h}$ light and dark cycle. Animals were fed a balanced diet of soaked wheat and palates supplemented with multivitamins and water ad libitum. The Institutional Animal Ethical Committee approved the protocol (IAEC, Reg. No. 1646/GO/Re/12/CPCSEA). 


\section{Experimentation}

Induction of hypothyroidism

Rats were induced hypothyroidism by giving oral administration of PTU at the dose of $10 \mathrm{mg} / \mathrm{kg}$ body weight orally for 30 days.

\section{Experimental design}

The experimental period comprised 60 days and healthy rats were divided into four groups $(\mathrm{n}=5)$ :

- Group 1: Animals of Group 1 receiving the vehicle, distilled water, served as control for 60 days.

- Group 2: Animals of Group 2 received PTU (10 mg/kg body weight) orally for 30 days to induce hypothyroidism.

- Group 3: Animals of Group 3, previously receiving PTU for 30 days followed by $A$. senegal bark extract ( $500 \mathrm{mg} / \mathrm{kg}$ body weight) for next 30 days of treatment period.

- Group 4: Animals of Group 4, previously receiving PTU for 30 days followed by Eltroxin $(0.5 \mu \mathrm{g} / 100 \mathrm{~g}$ body weight), respectively, for next 30 days of treatment period.

\section{Analysis of serum thyroxin hormone}

After completion of 60 days of the experiment, overnight fasting animals were sacrificed under ether anesthesia and blood sample was collected by direct cardiac puncture. Serum was separated by centrifugation and stored at $-200^{\circ} \mathrm{C}$ until analyzed for biochemical assessments. Serum $\mathrm{T}_{3}$ and $\mathrm{T}_{4}$ were analyzed using Biochemistry analyzer RX-50 and commercial diagnostic kit.

\section{Analysis of biochemical parameters}

Biochemical parameters such as blood sugar, urea, uric acid, serum creatinine, cholesterol, serum glutamic-oxaloacetic transaminase

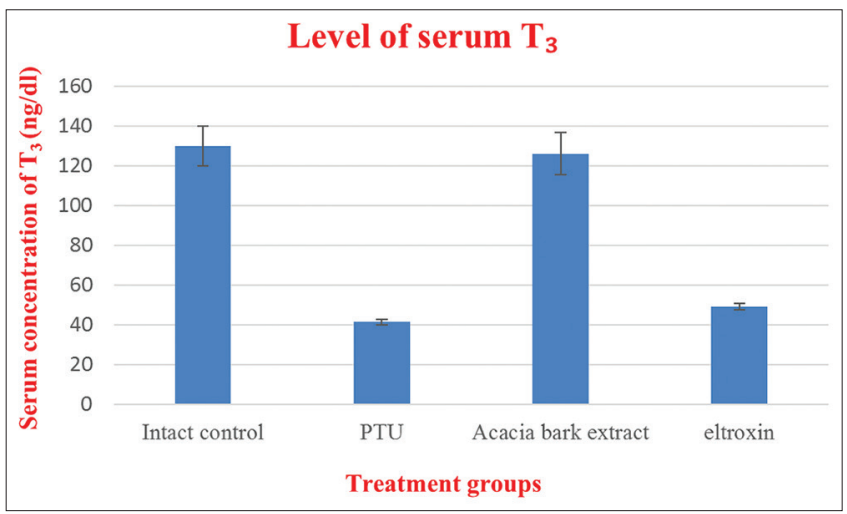

Fig. 1: Effect of Acacia senegal bark extract on serum $\mathrm{T}_{3}(\mathrm{ng} / \mathrm{dl})$ compare to other treatment groups (mean of 5 values \pm standard error of mean)

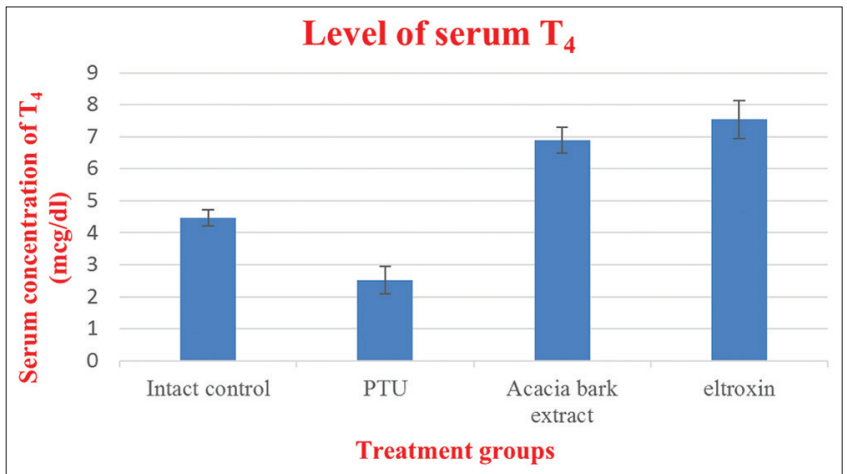

Fig. 2: Effect of Acacia senegal bark extract on serum $\mathrm{T}_{4}(\mathrm{mcg} / \mathrm{dl})$ compare to other treatment groups (mean of 5 values \pm standard error of mean)
(S.G.O.T), serum glutamic pyruvic transaminase (S.G.P.T), alkaline phosphate, and total protein were analyzed using Biochemistry analyzer RX-50 and commercial diagnostic kit.

\section{Analysis of organ's weight}

Vital organs such as thyroid, kidney, and heart were removed, cleared of fat and connective tissues. Each organ was weighed separately on electronic balance (ANAMED) to the nearest fraction.

\section{Statistical analysis}

Values of all biochemical parameters were expressed in terms of mean \pm standard error of mean and statistical analysis was done using one-way analysis of variance followed by Turkey's test using GraphPad Prism 7.0 software. The graphical representations were made using MS Excel 2013

\section{RESULTS}

\section{Effect on serum $T_{3}$ and $T_{4}$ levels}

PTU induction in rats caused a significant decrease $(p \leq 0.001)$ in total serum $\mathrm{T}_{3}$ and $\mathrm{T}_{4}$ when compared to the control group. The acacia bark-treated group found a non-significant change in $\mathrm{T}_{3}$ and significant $(\mathrm{p} \leq 0.01)$ change in $\mathrm{T}_{4}$ and Eltroxin found significant $(\mathrm{p} \leq 0.001)$ change in $T_{3}$ and significant $(p \leq 0.01)$ change in $T_{4}$ when compare to control. A significant elevation $(\mathrm{p} \leq 0.001)$ in $\mathrm{T}_{3}$ and $\mathrm{T}_{4}$ found in acacia bark-treated group while significant elevation ( $\mathrm{p} \leq 0.01)$ in $\mathrm{T}_{3}$ and highly significant $(\mathrm{p} \leq 0.001)$ elevation found in $\mathrm{T}_{4}$ of standard drug Eltroxintreated group when compared to PTU-treated group (Figs. 1 and 2).

\section{Effect on organ's weight}

Changes in organ's weight of animals were studied to compare it with control and other treatment groups of 60-day experiment. Highly significant $(p \leq 0.001)$ change in weight of thyroid and non-significant changes found in the heart and kidney of PTU-induced group when compared to control. When acacia bark-treated group compared with control, the weight of the thyroid showed significant $(p \leq 0.01)$ change and non-significant changes found in weight of heart and

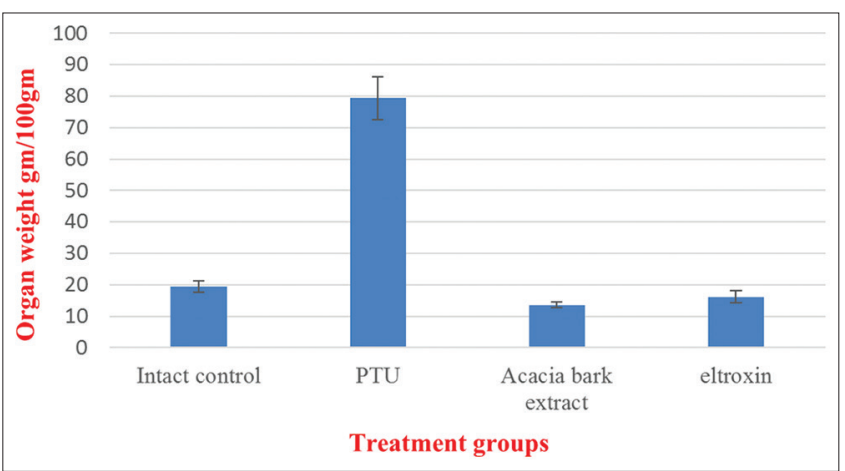

Fig. 3: Changes in weight of thyroid of intact control under various experimental conditions of 60-day treatment (mean of 5 values \pm standard error of mean)

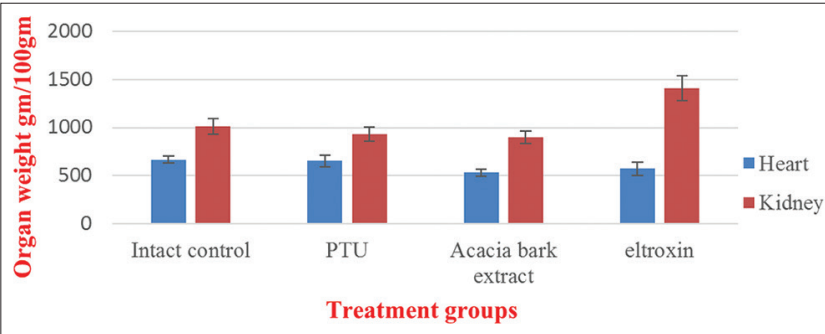

Fig. 4: Changes in weight of heart and kidney of intact contro under various experimental conditions of 60-day treatment (mean of 5 values \pm standard error of mean) 
kidney. Thyroid, heart, and kidney weights were found non-significant change in Eltroxin-treated group. Compared with PTU-treated group, acacia bark treatment group showed significant $(p \leq 0.001)$ change in weight of thyroid, non-significant changes in weight of heart and kidney. A significant $(\mathrm{p} \leq 0.001)$ change in thyroid, non-significant change in heart, but significant $(\mathrm{p} \leq 0.01)$ change found in kidney of Eltroxin-treated group compared to PTU-treated group (Figs. 3 and 4).

\section{Effect on biochemical parameters}

Administration of PTU in rats caused significant changes in biochemical parameters when compared to the control group. The treatment of A. senegal bark extract caused significant reduction by $15.76 \%$ (blood sugar), 31.53\% (blood urea), 26.08\% (serum creatinine), $76.41 \%$ (uric acid), $89 \%$ (S.G.O.T.), and $92.97 \%$ (S.G.P.T.) and elevation by $60.09 \%$ (cholesterol), $42.22 \%$ (alkaline phosphate), and $49.54 \%$ (serum total protein), whereas there was significant increase found in standard drug Eltroxin-treated group by $30.40 \%$ (blood sugar), 186.98\% (serum alkaline phosphatase), and $49.54 \%$ (serum total protein) but significant reduction by $42.71 \%$ (blood urea), $17.39 \%$ (serum creatinine), 79.55\% (serum uric acid), 15.68\% (cholesterol), 88.57\% (S.G.O.T.), and $94.43 \%$ (S.G.P.T.) compared to PTU-treated group (Table 1).

\section{DISCUSSION}

In the present study, Albino rats ( $R$. norvegicus) of Sprague Dawley strain were used and hypothyroidism was induced by the administration of PTU followed by the treatment of both Eltroxin and A. senegal bark extract. Induction of PTU decreases the level of both serum triiodothyronine $\left(\mathrm{T}_{3}\right)$ and tetraiodothyronine $\left(\mathrm{T}_{4}\right)$ consequently causing thyroid hypertrophy as reported previously [11]. PTU influences the oxidation of iodine, obstructs the process of deiodination of tyrosyl residue and their coupling hormone formation [12], hence, inhibits the conversion of $\mathrm{T}_{4}$ to $\mathrm{T}_{3}$ [13], and it was also found in this investigation. Levothyroxine is recommended to hypothyroid patients regarding their health status such as age, weight, cardiovascular diseases, and duration of hypothyroidism [14]. Commercial drug Eltroxin (common name levothyroxine) was used in this experiment to treat hypothyroidism as it suppresses the serum TSH concentration [15] and increases the level of $\mathrm{T}_{3}$ and $\mathrm{T}_{4}$ which shows similarity with previous studies done by Woeber [16] and with our study also. The level of $\mathrm{T}_{3}$ and $\mathrm{T}_{4}$ after administration of $A$. senegal bark extract in PTU-induced hypothyroid animals was near about to intact control group which points out the efficacy of plant drug. PTU-treated hypothyroid animals following A. senegal bark extract and Eltroxin treatment groups showed changes consequently in thyroid, heart, and kidney weight. A. senegal bark extract showed thyroid-stimulating activity which might be an outcome that it affects 5 '-monodeiodinase enzyme which converts $\mathrm{T}_{4}$ into $\mathrm{T}_{3}$, the main origin of $\mathrm{T}_{3}$ production as suggested by earlier study [17]. It is observed that many other plant extracts have been reported to exhibit thyroid-stimulating activity [18-22]. A. senegal bark extract improves the changed serum biochemistry of PTU-induced hypothyroid animals which is also supported by previous study of Batra et al. [10], who demonstrated that $A$. senegal bark extract ameliorates the blood glucose level, urea, and creatinine. The extract also showed decreased level of hepatic enzyme activity in comparison to the hypothyroid rats which might be the result of glycosides, flavonoids, and triterpenes, and a phenolic compound presents in a plant that shows hepatoprotective activity [23]. It was observed by Seif et al. that $A$. senegal extract lowered the hepatic markers, reinstates the activities of enzymes to normal [24], and thus ratifies the potency of this extract to reduce the complexity of biochemical parameters which were found in hypothyroid animals. A. senegal bark contains some tannin, saponins, and sterols like active phytochemicals which have antibacterial activity [25]. The activity of $A$. senegal bark extract to stimulate thyroid hormone might be an outcome of plant-derived active components. These active components are used as hormone replacement therapy which affects the feedback mechanism, biosynthesis, secretion, metabolism, transport, distribution, and action of thyroid hormone [26]. Thus, this study put

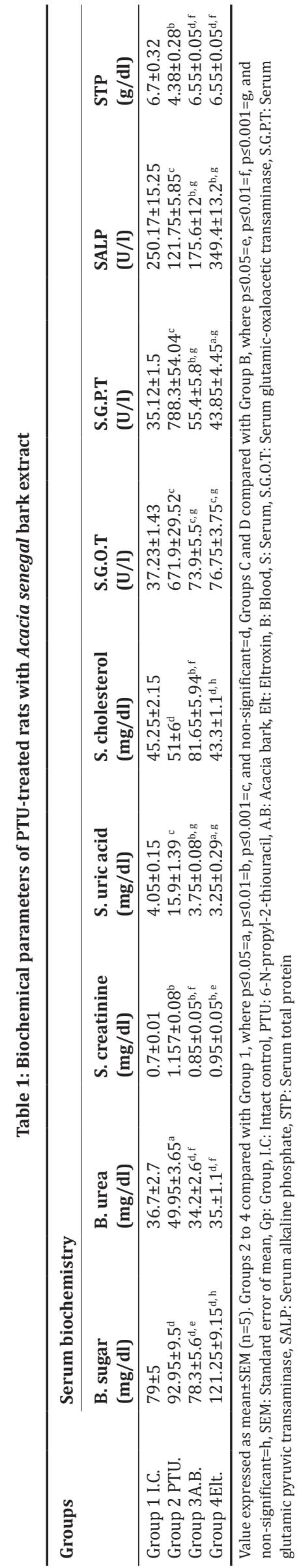


forward that $A$. senegal bark extract can be used to cure hypothyroidism without any side effects.

\section{CONCLUSION}

The present study concludes that the activity of $A$. senegal bark extract is just like Eltroxin which is beneficial to treat hypothyroidism, and it has thyroid hormone stimulating activity which increases the serum $\mathrm{T}_{3}$ and $\mathrm{T}_{4}$ levels.

\section{ACKNOWLEDGMENT}

We would like to thank the Department of Zoology, Jai Narain Vyas University, Jodhpur (Raj.), for providing all necessary amenities.

\section{AUTHORS' CONTRIBUTION}

This research work was advocated and designed by Ashok Purohit and experimental work was done by Dheeraj Jangid. Authors drafted and approved the final manuscript.

\section{CONFLICTS OF INTEREST}

The authors declare that they have no conflicts of interest.

\section{REFERENCES}

1. Ramakrishnan S, Keerthieshwar V, Forona B, Sowmiya S, Swetha S, Muthusarvanan $\mathrm{S}$, et al. Identification of bioactive lead compound against central hypothyroidism-an in silico approach. Int J ChemTech Res 2017;10:60-5

2. Swathi N, Kumar VV, Farjana M, Vishnuvardhan M, Munendra G, Kumar VA. Prospective observational study on prevalence of hypothyroidism in a tertiary care teaching hospital. Int J Pharm Pharm Sci 2018;10:186-91.

3. Veni KD, Kundoor N, Bashetti S, Rayaprolu P. Altered lipid profile in hypothyroidism: A biochemical viewpoint. Asian J Pharm Clin Res 2018;11:64-9

4. Nila KM, Mekhana VD, Nair SR. Anxiety, depression, and self-care management among patients with hypothyroidism. Asian J Pharm Clin Res 2018;11:337-40.

5. Hebbar S, Kumar S, Amin S, Doizode S. Subclinical hypothyroidism in pregnancy; Is there a need for pharmacological intervention? Int $\mathrm{J}$ Pharm Pharm Sci 2017;9:186-91

6. Khalawi AA, Al-Robai AA, Khoja SM, Ali SS. Can Nigella sativa oil (NSO) reverse hypothyroid status induced by PTU in rat? Biochemical and histological studies. Life Sci J 2013;10:802-11.

7. Ram H, Jatwa R, Purohit A. Anti athrosclerotic and cardio protective potentials of Acacia senegal seed in diet induced atherosclerosis in rabbits. Biochem Res Int 2014;2014:6.

8. Marwah RG, Fatope MO, Mahrooqi RA, Verma GB, Abadi HA, Al-Burtamani SK. Antioxidant capacity of some edible and wound healing plants in Oman. Food Chem 2007;101:465-70.
9. Alsadeg MA, Koko WS, El-badri E, Kabbashi AS, Dahab MM, Garbi MI, et al. In vitro anthelminthic activity of the methanol stem bark extract of Acacia senegal against Fasciola gigantica. Int Invent J Biochem Bioinformatics 2015;3:18-22.

10. Batra S, Batra N, Nagori BP. Preliminary phytochemical studies and evaluation of anti-diabetic activity of stem bark of Acacia Senegal (L.) wild.in alloxan induced diabetic albino rats. Am J Phytomed Clin Ther 2013;1:611-16

11. Sandro VD, Chevrier $M$, Boddaert A, Melcion C, Cordier A Richert L. Comparison of the effects of propylthiouracil, amiodarone, diphenylhydantoin, phenobarbital and 3-methylcholathrene on hepatic and renal T4 metabolism and thyroid gland function in rats. Toxicol Appl Pharmacol 1991;111:263-78

12. Richards JB, Ingbar SH. The effects of propylthiouracil and perchlorate on the biogenesis of thyroid hormone. Endocrinology 1959;65:198-207.

13. Oppenheimer JH, Sahwariz HL, Martin SI. Propylthiouracil inhibits the conversion of L-thyroxin to L-Triiodothyronine. J Clin Invest 1972;51:2493-7.

14. Tewthanom K, Jongjaroenprasert W. The pharmacokinetics of 2 doses $(50 \mu \mathrm{G}$ and $100 \mu \mathrm{G})$ levothyroxine treatment in athyreotic patients. Int J App Pharm 2016;8:66-8.

15. Mandel SJ, Brent GA, Larsen PR. Levothyroxine therapy in patients with thyroid disease. Ann Intern Med 1993;119:492-502.

16. Woeber KA. Levothyroxine therapy and serum free thyroxine and free triiodothyronine concentrations. J Endocrinol Invest 2002;25:106-9.

17. Panda S, Kar A. Guggulu (Commiphora mukul) potentially ameliorates hypothyroidism in female mice. Phytother Res 2005;19:78-80.

18. Panda S, Kar A. Changes in thyroid hormone concentrations after administration of Ashwagandha root extract to adult male mice. J Pharm Pharmacol 1998;50:1065-8.

19. Panda S, Kar A. Withania sominifera and Bauhinia purpurea in the regulation of circulating thyroid hormone concentration in female mice. J Ethnopharmacol 1999;67:233-9.

20. Tahiliani P, Kar A. Achyranthes aspera elevates thyroid hormone levels and decreases hepatic lipid peroxidation in male rats. J Ethanopharmacol 2000;71:527-32.

21. Kar A, Panda S, Bharti S. Relative efficacy of three medicinal plant extract in the alteration of thyroid hormone concentrations in male mice. J Ethanopharmacol 2002;81:281-5.

22. Saxena V, Dharmveer, Gupta R, Shubhini AS. Ficus carica leaf extract in regulation of hypothyroidism using elisa technique. Asian J Pharm Clin Res 2012;5:44-8

23. Adewusi EA, Afolayan AJ. A review of natural product with hepatoprotective activity. J Med plant Res 2010;4:1318-34

24. Seif MM, Farid OA, Aboulthana WM. Evalution of the protective effect of Acacia senegal extract against di-(2-ethylhexyl phthalate) induced hepato-and neurotoxicity in rats. Ann Res Rev Bio 2017;19:1-17.

25. Okoro SO, Kawo AH, Arzai AH. Phytochemical screening, antibacterial and toxicological activities of Acacia senegal extracts. Bayero J Pure Appl Sci 2012;5:163-70

26. Hamann I, Seidlova-Wuttke D, Wuttke W, Kohrle J. Effects of iso flavonoids and other plant-derived compound on the hypothalamuspituitary-thyroid hormone axis. Maturitas 2006;55:14-25. 